Index of Volume 76 (1997)

Issue 1/2

Editorial

R. M. Klopries, R. Dóczi, S. Sudár, J. Csikai, S. M. Qaim

Excitation Functions of some Neutron Threshold Reactions on ${ }^{89} \mathrm{Y}$ in the Energy Range of 7.8 to 14.7 MeV

Xiangzhong Kong, Yongchang Wang,

Jingkang Yang, Junqian Yuan

Cross Sections for (n,p), (n, $\alpha)$ and $(n, 2 n)$ Reactions on Rare-Earth Isotopes at $14.7 \mathrm{MeV}$. . . . . . .

S. Takács, M. Sonck, A. Azzam, A. Hermanne, F. Tárkányi

Activation Cross Section Measurements of Deuteron Induced Reactions on nat $\mathrm{Ni}$ with Special Reference to Beam Monitoring and Production of ${ }^{61} \mathrm{Cu}$ for Medical Purpose

S. V. Thakare, B. S. Tomar

Production of ${ }^{111} \mathrm{In}$ by ${ }^{7} \mathrm{Li}+$ nat. Ag for Perturbed Angular Correlation Applications . . . . . . . .

O. Stéphan, $M$. Carrier

Preparation of Thin $\alpha$-Particle Sources Using Polypyrrole Films Functionalized by Alkylammonium Groups . . . . . . . . . . . . . .

P. Zeh, K. R. Czerwinski, J. I. Kim

Speciation of Uranium in Gorleben Groundwaters

V. S. Koltunov, R. J. Taylor, O. A. Savilova, G. I. Zhuravleva, I. S. Denniss, A. L. Wallwork Kinetics and Mechanism of the Oxidation of Neptunium(IV) by Nitric Acid in Tributyl Phosphate Solution ................

I. Pashalidis, K. R. Czerwinski, Th. Fanghänel, J. I. Kim

Solid-Liquid Phase Equilibria of Pu(VI) and U(VI) in Aqueous Carbonate Systems. Determination of Stability Constants

S. S. Shoup, C. E. Bamberger

On the Formation of Americium- and Neptunium-

Containing Titanates . . . . . . . . . . .
V. S. Koltunov, R. J. Taylor, T. V. Gomonova,

I. S. Denniss

The Oxidation of Hydroxylamine by Technetium(VII) in Hydrochloric Acid . . . . . . . . 71

P. G. Allen, G. S. Siemering, D. K. Shuh,

J. J. Bucher, N. M. Edelstein, C. A. Langton,

S. B. Clark, T. Reich, M. A. Denecke

Technetium Speciation in Cement Waste Forms Determined by X-ray Absorption Fine Structure Spectroscopy . . . . . . . . . . . . . 77

Jingtao Wang, Xiangyun Wang, Yi Wang, Yuanfang Liu

A New Method for Synthesis of Boronic Acid Adducts of Technetium(III) Dioxime . . . . . . . . 87

Liu Chunli, Li Shushen, Wang Zhiming, Guo Zede, Zhao Yingjie, Li Zhentang, Jiang Ling

Migration of Radionuclides ${ }^{85} \mathrm{Sr},{ }^{134 / 137} \mathrm{Cs}$ and ${ }^{60} \mathrm{Co}$ in Unsaturated Chinese Loess . . . . . . . . . . 91

S. P. Mishra, V. K. Singh, D. Tiwari

25 Inorganic Particulates in Removal of Toxic Heavy Metal Ions. Efficient Removal of Cadmium Ions from Aqueous Solution by Hydrous Zirconium Oxide ................. 97

T. J. Haverlock, P. V. Bonnesen, R. A. Sachleben, B. A. Moyer

Applicability of a Calixarene-Crown Compound for the Removal of Cesium from Alkaline Tank Waste 103

M. L. P. Reddy, A. D. Damodaran,

M. C. Somasekhara Reddy

Radiochemical Extraction and Separation of Mercury(II) from Zinc(II) and Cadmium(II) with Cyanex 471X . . . . . . . . . . . 109

\section{Issue 3}

D. M. Giaquinta, L. Soderholm, S. E. Yuchs, S. R. Wasserman The Speciation of Uranium in a Smectite Clay: Evidence for Catalysed Uranyl Reduction . . . . . . 113 
P. K. Mohapatra, P. S. Mansingh,

R. Veeraraghavan, V. K. Manchanda, K. C. Dash Liquid-Liquid Extraction of Dioxouranium(VI) with a Mixture of 3-Phenyl-4-benzoyl-5-isoxazolone and Neutral Oxodonors: A Thermodynamic Study . . . . . . . . . . . . . 123

Jing Chen, Rongzhou Jiao, Yongjun Zhu

A Cross-flow Hot Test for Separating Am from Fission Product Lanthanides by Bis(2,4,4-trimethylpentyl)dithiophosphinic Acid Extraction . . . . . 129

Th. Könnecke, Th. Fanghänel, J. I. Kim

Thermodynamics of Trivalent Actinides in Concentrated Electrolyte Solutions: Modelling the Chloride Complexation of $\mathrm{Cm}(\mathrm{III})$. . . . . . . . . . . . 131

Wen Ruiyuan, Gao Hongcheng, Wang Xiangyun, Liu Yuanfang

Diffusion of Fission Fragment Nuclides in Granite 137

Jae Owan Lee, Kun Jai Lee, Won Jin Cho

Sorption and Diffusion of I-125 and Sr-90 in a Mixture of Bentonite and Crushed Granite Backfill of a Radioactive Waste Repository . . . . . . . . . 143

Y. Fujikawa, M. Fukui

Radionuclide Sorption to Rocks and Minerals: Effects of $\mathrm{pH}$ and Inorganic Anions. Part 1. Sorption of Cesium, Cobalt, Strontium and Manganese . . 153

Y. Fujikawa, M. Fukui

Radionuclide Sorption to Rocks and Minerals: Effects of $\mathrm{pH}$ and Inorganic Anions. Part 2. Sorption and Speciation of Selenium . . . . . . 163

\section{Issue 4}

K. Tsukada, N. Shinohara, I. Nishinaka,

S. Ichikawa, Y. Nagame, K. Sueki, T. Kobayashi,

H. Nakahara, M. Tanikawa, T. Ohtsuki

Highly Asymmetric Mass Division in Low-Energy

Proton-Induced Fission of ${ }^{232} \mathrm{Th}$ and ${ }^{244} \mathrm{Pu}$. . . . 173
R. Delmas, C. Loos-Neskovic, B. Bartos,

A. Bilewicz, M. Hussonnois, G. Ardisson

Searching for Cluster Decay of ${ }^{232} \mathrm{Th}$ : A Chemical

Separation Scheme for Sodium-24 from Thorium

P. Sahoo, S. V. Narasimhan, S. E. Kannan

Preparation of an Electrodeposited Source of ${ }^{54} \mathrm{Mn} 185$

\section{N. Berryman, Th. Probst}

Rapid Determination of ${ }^{90} \mathrm{Sr}$ by Electrothermal Vaporization-Inductively Coupled Plasma Mass Spectrometry (ETV-ICP-MS) . . . . . . . . . . . . 19

É. Sarkadi, Z. Kovács, L. Andó, F. Szelecsényi

Preparation of $\left[{ }^{11} \mathrm{C}\right]$ Labelled Methyl Iodide Using Aqueous HI Adsorbed on Alumina . . . . . . . 197

\section{H. Imaizumi, K. Nishiwaki, N. Kano}

Effect of the Number of Methylene Groups per Molecule on the Reactivity of Both Amino and Carboxyl Groups in Hydrogen-Isotope Exchange Reaction . . . . . . . . . . . . 201

M. Mufazzal Saeed, M. Abdul Qayyum, Akbar Ali Synergic Extraction of Eu(III) with 3-Methyl-1phenyl-4-trifluoroacetyl-2-pyrazolin-5-one (HPMTFP) and Tribenzylamine (TBA) from Perchlorate Media .............. 205

C. Den Auwer, C. Madic, J. C. Berthet, M. Ephritikhine, J. J. Rehr, R. Guillaumont X-Ray Absorption Spectroscopy of Organouranium Compounds in the $(+\mathrm{V})$ and $(+\mathrm{IV})$ Oxidation States . . . . . . . . . . . . . 211

M. Del Nero, B. Madé, G. Bontems, A. Clément Adsorption of Neptunium(V) on Hydrargilite . . 219

Author Index of Volume 76 . . . . . . . . . . 229 


\section{Radiochimica Acta}

\section{Volume $76 \cdot$ Issue $4 \cdot 1997$}

K. Tsukada, N. Shinohara, I. Nishinaka,

S. Ichikawa, Y. Nagame, K. Sueki, T. Kobayashi, H. Nakahara, M. Tanikawa, T. Ohtsuki

Highly Asymmetric Mass Division in Low-Energy Proton-Induced Fission of ${ }^{232} \mathrm{Th}$ and ${ }^{244} \mathrm{Pu}$

R. Delmas, C. Loos-Neskovic, B. Bartos,

A. Bilewicz, M. Hussonnois, G. Ardisson

Searching for Cluster Decay of ${ }^{232} \mathrm{Th}$ : A Chemical

Separation Scheme for Sodium-24 from Tho-

rium ................ 181

P. Sahoo, S. V. Narasimhan, S. E. Kannan

Preparation of an Electrodeposited Source of

${ }^{54} \mathrm{Mn} \ldots \ldots \ldots . . \ldots 185$

N. Berryman, Th. Probst

Rapid Determination of ${ }^{90} \mathrm{Sr}$ by Electrothermal Vaporization-Inductively Coupled Plasma Mass Spectrometry (ETV-ICP-MS)

É. Sarkadi, Z. Kovács, L. Andó, F. Szelecsényi Preparation of $\left[{ }^{11} \mathrm{C}\right]$ Labelled Methyl Iodide Using Aqueous HI Adsorbed on Alumina . . . . . . 197

H. Imaizumi, K. Nishiwaki, N. Kano

Effect of the Number of Methylene Groups per Molecule on the Reactivity of Both Amino and Carboxyl Groups in Hydrogen-Isotope Exchange Reaction . . . . . . . . . . . . . 201

M. Mufazzal Saeed, M. Abdul Qayyum, Akbar Ali Synergic Extraction of Eu(III) with 3-Methyl-1phenyl-4-trifluoroacetyl-2-pyrazolin-5-one (HPMTFP) and Tribenzylamine (TBA) from Perchlorate Media . . . . . . . . . . . 205

C. Den Auwer, C. Madic, J. C. Berthet,

M. Ephritikhine, J. J. Rehr, R. Guillaumont

X-Ray Absorption Spectroscopy of Organouranium Compounds in the (+V) and (+IV) Oxidation States . . . . . . . . . . 211

M. Del Nero, B. Madé, G. Bontems, A. Clément Adsorption of Neptunium(V) on Hydrargilite . . 219

Author Index of Volume $76 \ldots 229$ 
